Kumar D (2015) Building sustainable competitive advantage: through executive enterprise leadership. Gower Publishing, New York

Lin H, Sun Y, Wang B (2012) Research and application on information resources planning for university. In: Proceedings of the 2nd international conference on computer and information applications (ICCIA 2012), pp 1497-1500

Marabelli M, Galliers RD (2017) A reflection on information systems strategizing: the role of power and everyday practices. Inf Syst J 27(3):347-366

McFarlan FW, McKenney JL, Pyburn P (1983) The information archipelago - plotting a course. Harv Bus Rev 61(1):145-156

Peppard J, Galliers RD, Thorogood A (2014) Information systems strategy as practice: micro strategy and strategizing for IS. J Strateg Inf Syst 23(1):1-10

Reynolds GW (1992) Information systems for managers, 2nd edn. West Publishing Company, St. Paul

Tukana S, Weber R (1996) An empirical test of the strategic-grid model of information systems planning. Decis Sci 27(4):735-765

Ward J, Griffiths P, Whitmore P (1990) Strategic planning for information systems. Wiley, Chichester

Wijaya WM (2016) Strategic information system planning: information systems required in vocational school models. In: Proceedings of the 6th international conference on educational, management, administration and leadership (6TH ICEMAL 2016), vol 14, pp 67-71

\section{IT on Teaching and Learning Process of Visually Impaired Students}

\author{
Sara Isabel Moça Ramos ${ }^{1}$ and
}

António Manuel Valente de Andrade ${ }^{2}$

${ }^{1} \mathrm{CEDH}$ - Centre for Studies in Human

Development, Faculty of Education and

Psychology, Universidade Católica Portuguesa

(Oporto Regional Centre), Porto, Portugal

${ }^{2}$ CEGE - Research Centre in Management and Economics, Católica Porto Business School, Universidade Católica Portuguesa (Oporto Regional Centre), Porto, Portugal

\section{Synonyms}

Assistive technology; Cognitive computing; E-learning; Inclusive education; Information technology; Teaching and learning process; Visual impairment

\section{Introduction}

Nowadays, technology is an essential component in our society. Considering its impact in the educational system, Information Technology (IT) cannot be dissociated from the educational process and from pedagogical practices. The role of technology is so essential in our lives today that it is necessary that students develop organizational, problem-solving, and critical skills to meet the demands of an increasingly technological work world and be fully integrated members of the society.

Since the mid-1980s, the trend has been the inclusion or inclusive education, in which the emphasis is placed on students with disabilities being included in regular education system. This inclusive model focuses on students belonging in general classrooms, and the successful inclusive education happens primarily through accepting, understanding, and attending to student's differences and diversity.

To achieve inclusion, it is necessary to be aware that all children and students have the capacity for learning and for educational development. Therefore, each school must find ways to deal with the difference, adapting teaching processes to the characteristics and conditions of each student, mobilizing the means at their disposal so that everyone learns and participates in the learning process. IT is crucial for people with disabilities and special educational needs and using them in schools to support inclusion can enable them to communicate, be included in lessons, be more autonomous, and learn more effectively (BECTA 2003).

Visual impairment (blindness, partial sight, and color blindness) is a disability category and includes the range from low vision, students who are partially sighted and can generally read print, to full blindness, the ones who are blind and cannot read print. Students with visual impairment, depending on their individual circumstances, "may not be able to rely on the sense of sight to obtain information, observe their surroundings, and learn about the world" (Presley and D'Andrea 2008, p. 4). The implications of not being able to use all visual capability can affect aspects of life and learning of students 
with visual impairment. Thus, abstract reasoning and conceptual thinking are often problem areas for these students.

Visual impairment is inevitably associated with several limitations regarding electronic accessibility, but students with vision impairments cannot be excluded from technological evolution. Therefore, it is imperative that they benefit from technologies, promoting their digital inclusion, communication, autonomy, and involvement in learning.

\section{Assistive Technology (AT) and Digital Technology}

Information and communication technology (ICT) is a specific area of IT and when concerned with educational systems includes mainstream technologies, assistive technologies, media and accessible formats, educational software, and online learning environments (UNESCO 2011). Assistive technology is "software and technology which helps people with disabilities and special needs to overcome the additional challenges they face in communication and learning" (BECTA 2003, p. 3).

Technology innovations are a central factor to education. Much of the assistive technology for individuals with visual impairments has focus on accessing information (Kelly and Smith 2011); however, information technologies play several enabling roles for these students, such as enabling impairment compensation, accessing information, facilitating communication, assisting learning, arranging and sustaining support, increasing collaboration, and achieving social connection and participation (Pacheco et al. 2017). Yet, learners with visual impairment face difficulties with accessibility of websites, course learning management systems, and digital audio and video (Fichten et al. 2009b).

The first assistive technology devices were tools such as the slate and stylus, a handheld device, used to create braille. After these, manual braillewriters were developed, ensuring a faster production of texts with braille symbols, and in the early 1900s, audio technology, such as radios and recorders, arose (Kelly and Smith 2011). With the technological development, new technologies for people with visual impairment have been developed: braille embossers, advanced close-circuit televisions (CCTVs), scanners and optical character recognition software, computer screen readers, compact discs, and many other innovations that can help people with visual impairment (Kelly and Smith 2011), such as speech synthesizers, talking book libraries, and mobility-aid solutions for mobile phones.

Nowadays, many technologies which aim to decrease the impact of visually impairment are under development. In 2017, during the Low Vision Awareness Month, the National Eye Institute, part of the USA National Institutes of Health, highlighted new technologies and tools to help the 4.1 million Americans with visual impairments; among them, the co-robotic cane, the robotic glove that finds door handles and small objects, the smartphone crosswalk app, and the CamIO (camera input-output) that provides real-time audio feedback as the user explores an object (DeMott 2017).

Students with visual impairment have also difficulty in accessing graphical materials (Butler et al. 2017). In order to overcome this barrier, students can use technologies such as sonification, haptic feedback, integrated e-book delivery on touchscreen, and three-dimensional printed tactile models (Simui et al. 2018). These technologies have been developed to help individuals with visual impairment to access graphical information, though not yet in extensive use (Simui et al. 2018).

However, and despite the wide range of technological resources, there are many barriers in receiving and using them by students with visual impairment due to internal and external factors. The lack of awareness, services, products, and financial barriers are some of the issues mentioned by researchers and international organizations (Bhatt and Kumari 2015; UNICEF and WHO 2015). Furthermore, students with visual impairment are reluctant to use these tools, once they face frustration and social embarrassment and do not want to draw attention to themselves for fear of failing to handle them properly (Bhatt and Kumari 2015). 


\section{Learning by Social Media Platforms}

Besides ICT, IT also covers digital tools such as social media platforms, mobile devices, and applications, but yet, there is no empirical evidence of the role played by these last ones (Griffin-Shirley et al. 2017; Pacheco et al. 2017). Social networking services and portable devices are additional opportunities for accessing information and the preferred means of communication by students with visual impairment. These technological means are being used by these students as a complementary environment for informal and individualized learning (Pacheco et al. 2017). Computer mediates communication, both synchronous and asynchronous, and gives blind or partially sighted students the opportunity to participate actively in classroom activities, interact and communicate easily with their peers (Arrigo 2005).

Permvattana and Hollier (2013) refer that the ability to access online tutorials in YouTube, researching using Twitter, and sharing ideas using blogs conducts to benefits for education. The social network service Facebook is the most used networking service (Voykinska et al. 2016; $\mathrm{Wu}$ and Adamic 2014), and it is used as a communication channel, overcoming the constraints of time and space and making communication better and quicker (Pacheco et al. 2017). Wu and Adamic found that users with visual impairment "participate on Facebook (e.g. status update, comments, likes) as much as the general population, and receive more feedback (i.e., comments and likes) on average on their content" (2014, p. 3133). So, "students with vision impairments adapted social media to respond to their personal learning needs" (Pacheco et al. 2017, p. 8) and now use social media tools and applications to support online knowledge sharing and academic collaborations (Pacheco et al. 2017).

However, blind social networking services users face challenges in interacting with it due to "pervasive visual elements, complicated page structure, and infinitely scrolling feeds that are incompatible with screen readers" (Voykinska et al. 2016, p. 1593). Moreover, "the use of JavaScript to create highly dynamic web pages can cause problems for screen readers, and bugs related to accessibility can be harder to capture and reproduce" (Wu and Adamic 2014, p. 3133). As a drawback, all these problems cannot be suppressed by the W3C Web Content Accessibility Guidelines alone, because it has guidelines to make content accessible to a wider range of people with disabilities (Buzzi et al. 2012).

Despite this, the evolution of information technology and the specific development of assistive technologies are removing barriers and enabling the same access to people with visual impairment as anyone ( $\mathrm{Wu}$ and Adamic 2014). However, there is still much more that needs to be done to ensure universal accessibility to web content (Fichten et al. 2009a; Voykinska et al. 2016).

\section{Learning Through E-learning}

Though Internet is the main mean to access information, students with visual impairment appreciate "the fact that via ICTs they can search, retrieve and access a larger amount of information and from different sources" (Pacheco et al. 2017, p. 5). With the widespread of the Internet, it was possible to develop virtual learning environments and apply these systems in teaching and learning process. Nowadays, e-learning is becoming a valuable tool in visually impaired students' learning process (Kharade and Peese 2012) and has the potential to facilitate inclusion of these students (Fichten et al. 2009a). Kharade and Peese define e-learning:

as the delivery of a learning, training or education programme by electronic means covering a wide set of applications and processes, such as web-based learning, computer-based learning, virtual classrooms and digital collaboration. (2012, p. 440)

The same authors consider that e-learning stimulate remote learning for students with visual impairment, enable teachers to provide remote assistance to these students, and promote continuing education for visual impaired adults. So, elearning leads to "more effective and efficient methods for acquiring and transferring knowledge beyond the traditional classroom environments" (Buzzi et al. 2012, p. 125). 
Learners with visual impairments must adapt and use e-learning, as this is one of the most used tools in postsecondary education by teachers to support the learning process (Fichten et al. 2009a). E-learning leads to the inclusion of students with visual impairments in classrooms, facilitating the access to class materials without assistance (Fichten et al. 2009a). However, Fichten et al. (2009b) observed that there is a reduced use of e-learning by teachers of learners with visual impairments in colleges and universities and they have lack of knowledge working with it.

Educational materials created for sighted students are often inappropriate for learners with visual impairments; therefore, these students with disabilities face particular challenges at an e-learning environment due to the unsuccessful support of assistive technologies and learning materials accessible issues (Fichten et al. 2009a; Permvattana and Hollier 2013). Educational materials should be provided through several means: visual, auditory, and tactile (Buzzi et al. 2012), making them accessible to everyone, including people with disabilities.

\section{Teaching, Learning, and Information Technologies}

According to Teles (2011), visual impairment is perhaps the most undervalued area concerned to information technologies and special educational needs. However, the access to appropriate technology enables learners with visual impairment to better adjust to the traditional learning processes and use of sources of information as their peers (Alves et al. 2009).

Students with visual impairment have the right to expect the same level of education just like any other students, but they face relevant difficulties in terms of accessing and using electronic learning tools and struggle to maintain the required learning pace, leading this to lower achievements (Eligi and Mwantimwa 2017; Permvattana and Hollier 2013). According to UNICEF and WHO, "the correlation between low education outcomes and having a disability is often much stronger than the correlations with other characteristics" (2015, p. 16).
Almost all education is going digital. Onukotun's, cited by Eligi and Mwantimwa, reveals that information technologies "do not only enhance access to information but also promote education and lifelong learning" (2017, p. 88). Information technologies allow learners with visual impairment to access information and the general curriculum. They help to increase the independence of blind and partially sighted students, minimizing the deprivation of perceiving images, gestures, and colors. The use of computers, speech synthesizers, and screen magnifiers provide access and enable the production of digital information. Therefore, technologies are means to overcome the lack of vision, expanding opportunities to communicate and to develop personal autonomy; moreover, it stimulates cognitive development and enhances and leverages the appropriation of knowledge, skills, and information (Sá et al. 2007).

The speed on information processing by students with visual impairment is allowed and improved with the use of a screen reader for reading with audio support (Jackson 2012). Besides, it permits better understanding of texts, shortening the time required to complete the tasks (Jackson 2012; Pacheco et al. 2017). With the use of optical devices, research shows improvements in the students' silent reading speeds and comprehension rates (Corn et al. 2002).

Many studies emphasize the potential of using IT in education of people with visual impairment (Bhatt and Kumari 2015; Fuglerud 2011; Jackson 2012; Kelly and Smith 2011; Pacheco et al. 2017; Papadopoulos and Goudiras 2005; Pattillo et al. 2004; Wu and Adamic 2014; Zhou et al. 2012); however, few schools and teachers implement information technologies to successfully support learning and teaching process (Nwigbo and BK 2016). In this sense and contrary to other studies, Bano et al. (2011) research shows that braille literacy, for their sample, was more important than the computer software literacy in the education of students with visual impairment, having more positive responses towards the first one. The dissatisfaction with the computer education at these students' schools is highlighted in this research, as well as, the absence of teachers with technological required experience. 
In schools, the means are not always available or suited to the real needs of students with or without special education needs (Ribeiro et al. 2010). It is crucial that schools ensure access to appropriate and necessary technology to students with visual impairment (Abner and Lahm 2002), but more importantly, suit technology to education goals and standards, and have a vision for the use of it to support the curriculum (Nwigbo and BK 2016). It is important these students with special educational needs learn to use assistive technology to access electronic information, so they can participate more equally with their sighted classmates (Presley and D'Andrea 2008).

\footnotetext{
By keeping an open mind, becoming comfortable about technology and its pervasive role in our lives, encouraging students to explore and use technology to the fullest extent possible, and promoting skills through opportunities for practice, professionals working with students who are visually impaired can help them to excel in today's competitive world - and tomorrow's as well. (Presley and D'Andrea 2008, p. 16)
}

IT supports new learning experiences for students with visual impairment, providing and improving this way a quality education (UNESCO 2011), a wide range of opportunities and the quality of the teaching and learning process (Fuglerud 2011). Broadly speaking, the actual challenge is to provide technological access and training (technology education) for the students with visual impairment to support learning and teaching (educational technology) (Nwigbo and BK 2016), making the best use of technology throughout their academic progression.

However, it is important to emphasize that technologies by themselves do not mediate learning but just provide influence on learning strategies, so it could not be thought as a global solution but "should be considered as a support to the learning process" (Söderberg and Fellenius 2000, p. 70).

\section{Teachers' Role on Visually Impaired Learners' Education}

Despite the increasing independency of learners with visual impairments, all teachers are prominent elements in their educational process and have an important role to guide these students to overcome their difficulties and achieve academic success. Ramos and Andrade found on their study that teachers are aware that "ICT promote the transmission of knowledge and improve the teaching and learning process, contributing to academic success, autonomy and inclusion of students who are blind or partially sighted" (2016, p. 638).

However, many regular teachers are unprepared and fearful to deal with most of the tools and applications designed for students who are visually impaired (Ramos and Andrade 2016). This fact leads to a lower application of IT with learners with visual impairment (Ramos and Andrade 2016). Moreover, teachers are not reflecting IT on their daily classroom role due in part "to the pressures they perceived to meet their individual obligations of teaching a range of classes" (Hartnell-Young 2003, p. 2).

The use of IT by students who are visually impaired depends on the encouragement given by teachers and it is constrained by initial and continuous training acquired by those (Smith and Kelley 2007). Research indicate that teachers of learners with visual impairment do not have the necessary training on IT area (Abner and Lahm 2002; Ramos and Andrade 2016; Smith and Kelley 2007; Zhou et al. 2011); however, this lack of specific training is more severe for teachers in regular classroom than for special education teachers (Papadopoulos and Goudiras 2005). So, it is important that teachers get more training on how to work with visually impaired learners (Simui et al. 2018), as well as pedagogical support (Alves et al. 2009).

The teachers' lack of training is one of the significant problems which prevents them from achieving the full advantages of IT use in educational practices (Ribeiro et al. 2010). Teachers need time to plan, learn how to integrate technology and implement it (Nwigbo and BK 2016), thus taking advantage of their beliefs on IT potential as promoter of inclusive education (Alves et al. 2009; Ramos and Andrade 2016) and its positive impact on the curriculum (Nwigbo and BK 2016; Ramos and Andrade 2016).

With the current technological requirements and consequent application of IT at schools, it is a challenge for teachers to update and expand their 
skills so that their educational activities benefit from the potential of technological resources. Although the use of IT in schools is taken seriously by governments and educational systems, "there appear to be more critical steps and vital ingredients needed for the successful infusion of ICT into educational environments" (Nwigbo and BK 2016, p. 1).

With the technological development, teachers' role is changing, as well the traditional teaching methods have been challenged by technology-enhanced teaching and learning methods (Hämäläinen and Cattaneo 2015; HartnellYoung 2003). According to the research findings, traditional teaching is diminishing and is arising the role of the teacher as a facilitator, guiding and coaching for students' learning processes (Hämäläinen and Cattaneo 2015). The active role of teachers is becoming the booster to interaction processes related to learning tasks, and they are progressively working together with learners in new technology-enhanced learning contexts, such as technology-enhanced classrooms and virtual settings (Hämäläinen and Cattaneo 2015).

\section{New Challenges to Teaching and Learning Process}

IT allows students to achieve learning experiences "when and where they are needed" (Nwigbo and BK 2016, p. 5) and independency to what they learn. Besides, students making use of technology become more independent in the classroom and can discover solutions to problems both independently and collaboratively. Researches show that online interaction triggers the opportunity to share information from their peers (Pacheco et al. 2017). Therefore, IT promotes the cooperation and collaboration among learners within and beyond school, having a positive effect on teaching and learning process, "introducing news and better ways of learning and teaching" (Nwigbo and BK 2016, p. 6). Technology can support new types of learning possibilities (Hämäläinen and Cattaneo 2015), as well as promote students as active learners and with the desire of discovery and knowledge.
In education field, based on each individual student's needs, cognitive computing services data-driven artificial intelligence (AI) - provide content, planning, and intelligent activities to promote knowledge in an effective and personalized way. In fact, according to Coccoli, Maresca, and Stanganelli, "from the e-learning point of view [...], cognitive computing can be an accelerator for students' achievements, and a valuable support for the teachers" (2016, p. 62).

Cognitive computing can either support teachers in solving common students' issues, such as "school dropout, individualization of learning, customization of training path, etc., due to their capability of analysing data" (Coccoli et al. 2016, p.64). Teachers can adopt new tools of cognitive computing to conduct individualized experiences and provide a "range of activities to assist students to become critical thinkers, designers and problem solvers" (Nwigbo and BK 2016, p. 5).

Recently, several tools and platforms based on cognitive computing were created: Cognitive Reasoning Platform by Enterra; Deep Learning, by Microsoft; DeepMind, by Google; IDOL, delivered by HP; and Watson, by IBM. Digital interactions with students, promoted by these platforms, can enhance learners' performances and help educators personalize and adapt their approaches to students' results (Coccoli et al. 2016). To drive personalized teaching, IBM Watson Education offers teachers a new level of engagement and a detailed view of each student, including achievement, academic performance, attendance, behavior, and activities learned.

The mobile app market is growing, and it is providing accessible experiences for visually impaired smartphone users. Microsoft has released, on July 2017, the new free artificial intelligence application for Apple's iPhone, called Seeing AI (formally known as Deep Vision), designed for the low-vision community. This app uses mobile camera and describes people, text, currency, color, and objects that are being photographed. This app can turn the visual world into an audible experience (Microsoft n.d.) and can be applied in educational context to overcome visual barriers faced by these learners.

Artificial intelligence can make the educational experience more effective and engaging, both for 
students and teachers and "the current absence of sophisticated use of AI Technologies in schools, colleges, and universities may be explained by the lack of financial resources as well as the lack of data establishing the technologies' effectiveness" (Stone et al. 2016, p. 33).

Virtual assistants, sometimes called smart speakers, from Amazon, Apple, Google, and Microsoft, such as Alexa, Siri, Google's Assistant, and Cortana, respectively, are voice command platforms which can carry out a range of tasks. Therefore, applying these platforms in schools, students can interact with them and get real-time personal feedback. These can be useful in schools unlocking barriers for both students and teachers and a source of information and enhancing thought-provoking tasks. For example, these platforms can be used by learners with visual impairment to find library materials faster.

The arise of digital voice assistants in education is inevitable, so it is important that educational system explore how can it create more effective, engaging, and creative learning environment.

"New competencies are required by teachers of pupils with visual impairments in mainstream schools," opposing these "from the traditional model of training dating from the time of the special school and the 'sight class' era" (Söderberg and Fellenius 2000, p. 69). To achieve the real potential of IT as well as the important educational goals of students with visual impairment, it is essential that educators use IT in learning situations (Alves et al. 2009; Presley and D'Andrea 2008).

\section{Conclusions}

From the viewpoint of the implementation of IT in visually and partially sighted students teaching and learning process, research studies indicate that IT enables students to overcome barriers of learning, as well as develop their inclusion in the mainstream classrooms. Applying them to support education can lead to educational benefits such as improving learning and increasing communication skills, yet, not all students have positive feelings towards IT daily educational use.
Thereby the continuous development of IT, its implementation, for educational purposes, with students with visual special needs, has a long way to go. Educational community must be open-minded to exceed the traditional teaching model and place greater emphasis on the active role of students with visual impairment inside and outside classroom, using the available technological means, even those which are behind educators' comfort zone.

Even when technology is available, access may still be problematic. To avoid insecurity and frustration by students with visual impairment, dealing with accessible web issues, it is important to ensure full accessibility of the learning environment and the educational materials, following the W3C guidelines.

Therefore, material conditions of the schools should be strengthened, and a greater commitment must be done by the educational community, especially by teachers, to implement IT in learning and teaching process. Teachers refer barriers to the low use of technologies as a mean to optimize the learning process, such as time constraints; insufficient knowledge to adapt technological means to visually impaired learners' needs, reinforced with the deficiency of training on this specific technological area.

They can maximize the impact of IT on teaching and learning process by understanding the potential of it to support students with visual impairment and tailoring and adapting activities to involve these students in learning. Online discussion forums can be used to access information, advice, and guidance, as well as to share knowledge and for reflection among teachers in regular classroom and special education teachers. It is utterly important that all community get involved in this process.

\section{Cross-References}

- Assisting People with Vision Impairments Through Technology

- Assistive Technology and Inclusion, Philosophical Foundation

- ICT-Based Inclusive Education

- Teacher Education, Thinking About ICT 


\section{References}

Abner G, Lahm E (2002) Implementation of assistive technology with students who are visually impaired: teacher readiness. J Vis Impair Blindness 96(2):98-105

Alves C, Monteiro GBM, Rabello S, Gasparetto MERF, Carvalho KM (2009) Assistive technology applied to education of students with visual impairment. Rev Panam Salud Publica 26(02):148-152

Arrigo M (2005) E-learning accessibility for blind students. Recent Res Dev Learn Technol I: 422-426

Bano I, Naqvi SAH, Hashmi MA, Raza SA, Shaikh FM (2011) Comparative analysis of computer software and braille literacy to educate students having visual impairment. Aust J Bus Manag Res 1(8):85-89

BECTA (2003) What the research says about ICT supporting special educational needs (SEN) and inclusion. Retrieved from http://www.mmiweb.org.uk/publi cations/ict/Research_SEN.pdf

Bhatt A, Kumari A (2015) Assistive technology for the visually impaired children for their academic excellence. Glob J Eng Sci Soc Sci Stud 1:13-19

Butler M, Holloway L, Marriott K, Goncu C (2017) Understanding the graphical challenges faced by visionimpaired students in Australian universities. High Educ Res Dev 36(1):59-72. https://doi.org/10.1080/ 07294360.2016.1177001

Buzzi MC, Buzzi M, Leporini B, Mori G (2012) Designing e-learning collaborative tools for blind people. In: Pontes E, Silva A, Guelfi A, Kofuji ST (eds) E-Learning Long-Distance and Lifelong Perspectives. IntechOpen, pp 125-144 https://doi.org/10.5772/31377

Coccoli M, Maresca P, Stanganelli L (2016) Cognitive computing in education. J E-Learn Knowl Soc 12 (2):55-69

Corn AL, Wall RS, Jose RT, Bell JK, Wilcox K, Perez A (2002) An initial study of reading and comprehension rates for students who received optical devices. J Vis Impair Blindness 96(5):322-334

de Sá ED, de Campos IM, Silva MBC (2007) Atendimento Educacional Especializado - Deficiência Visual. Ministério da Educação e Cultura - Secretaria de Educação Especial, Brasília.

DeMott K (2017) Five innovations harness new technologies for people with visual impairment, blindness. Retrieved 9 Aug 2018, from https://nei.nih.gov/news/ briefs/five-innovations-harness-new-technologies-peopl e-visual-impairment-blindness

Eligi I, Mwantimwa K (2017) ICT accessibility and usability to support learning of visually-impaired students of Tanzania. Int J Educ Dev Using Inf Commun Technol (IJEDICT) 13(2):87-102

Fichten CS, Asuncion JV, Barile M, Ferraro V, Wolforth J (2009a) Accessibility of e-learning and computer and information technologies for students with visual impairments in postsecondary education. J Vis Impair Blindness 103(9):543-557

Fichten CS, Ferraro V, Asuncion JV, Chwojka C, Barile M, Nguyen MN et al (2009b) Disabilities and e-learning problems and solutions: an exploratory study. Educ Technol Soc 12(4):241-256
Fuglerud KS (2011) The barriers to and benefits of use of ICT for people with visual impairment. In: Stephanidis $\mathrm{C}$ (ed) Universal access in human-computer interaction - design for all and eInclusion. Springer, Berlin, pp 452-462

Griffin-Shirley N, Banda DR, Ajuwon PM, Cheon J, Lee J, Park HR, Lyngdoh SN (2017) A survey on the use of mobile applications for people who are visually impaired. J Vis Impair Blindness 111(4): 307-323

Hämäläinen R, Cattaneo A (2015) New TEL environments for vocational education-teacher's instructional perspective. Vocat Learn 8(2):135-157. https://doi.org/ $10.1007 / \mathrm{s} 12186-015-9128-1$

Hartnell-Young E (2003) From facilitator to knowledgebuilder: a new role for the teacher of the future. In: Dowling C, Lai KW (eds) Information and Communication Technology and the Teacher of the Future. IFIP The International Federation for Information Processing. (pp. 159-163). Springer, Boston, MA

Jackson RM (2012) Audio-supported reading for students who are blind or visually impaired. Retrieved from http://aim.cast.org/learn/practice/future/audio_supported reading

Kelly SM, Smith DW (2011) The impact of assistive technology on the educational performance of students with visual impairments: a synthesis of the research. J Vis Impair Blindness 106(2):73-83

Kharade K, Peese H (2012) Learning by e-learning for visually impaired students: opportunities or again marginalosation? E-Learn Digit Media 9(4):439-448

Microsoft (n.d.) Seeing AI: an app for visually impaired people that narrates the world around you. Retrieved 21 Aug 2018, from https://www.microsoft.com/en-us/ garage/wall-of-fame/seeing-ai/

Nwigbo S, BK M (2016) The impact of technology on the teaching and learning process. IOSR J Mob Comput Appl 3(2):235-257. https://doi.org/10.4018/978-15225-2838-8.ch011

Pacheco E, Yoong P, Lips M (2017) The role of ICTs in students with vision impairments' transition to university. In: CONF-IRM 2017 proceedings. p 34. Retrieved from http://aisel.aisnet.org/confirm2017/34/

Papadopoulos KS, Goudiras DB (2005) Accessibility assistance for visually-impaired people in digital texts. Br J Vis Impair 23:75-83

Pattillo ST, Heller KW, Smith M (2004) The impact of a modified repeated-reading strategy paired with optical character recognition on the reading rates of students with visual impairments'. J Vis Impair Blindness 98 (1):28-46

Permvattana R, Hollier S (2013) Where e-learning models and social media collide: supporting the future education of blind and VI learners. In: Accessible e-learning online symposium 16 December 2013. Retrieved from https://www.w3.org/WAI/RD/2013/e-learning/paper1/

Presley I, D'Andrea FM (2008) Assistive technology for students who are blind or visually impaired: a guide to assessment. American Foundation for the Blind, New York

Ramos S, Andrade A (2016) ICT in Portuguese reference schools for the education of blind and partially sighted 
students. Educ Inform Technol 21(3):625-641. https:// doi.org/10.1007/s10639-014-9344-6. Springer

Ribeiro J, Almeida AM, Moreira A (2010) A utilização das TIC na educação de alunos com necessidades educativas especiais: resultados da aplicação piloto do inquérito nacional a coordenadores TIC/PTE. Indagatio Didactica 2(1):94-124

Simui F, Kasonde-Ngandu S, Cheyeka AM, Simwinga J, Ndhlovu D (2018) Enablers and disablers to academic success of students with visual impairments: a 10-year literature disclosure, 2007-2017. Br J Vis Impair 36(2):163-174. https://doi.org/10.1177/02646196177 39932

Smith DW, Kelley P (2007) A survey of assistive technology and teacher preparation programs for individuals with visual impairments. J Vis Impair Blindness 101(7):429-433

Söderberg A, Fellenius K (2000) Preserving and developing a knowledge of the education of pupils with a visual impairment through open and distance learning in Sweden. Br J Vis Impair 18:69-72

Stone P, Brooks R, Brynjolfsson E, Calo R, Etzioni O, Hager G, ..., Teller A (2016) Artificial intelligence and life in 2030. In: One hundred year study on artificial intelligence: report of the 2015-2016 study panel. Stanford University, Stanford. September 2016. Retrieved from http://ai100.stanford.edu/2016-report

Teles RO (2011) Mãos que Veem: Recursos e Acessibilidade para a Deficiência Visual. In: Cadernos SACAUSEF VI - A Acessibilidade de Recursos Educativos Digitais. DGIDC, Lisboa, pp 83-92

UNESCO (2011) Accessible ICTs and personalized learning for students with disabilities: a dialogue among educators, industry, government and civil society. UNESCO, Paris
UNICEF \& WHO (2015) Assistive technology for children with disabilities: creating opportunities for education, inclusion and participation: a discussion paper. World Health Organization, Geneva

Voykinska V, Azenkot S, Wu S, Leshed G (2016) How blind people interact with visual content on social networking services. In: Proceedings of the 19th ACM conference on computer-supported cooperative work \& social computing (CSCW '16). ACM, New York, pp 1584-1595. https://doi.org/10.1145/2818048. 2820013

Wu S, Adamic L (2014) Visually impaired users on an online social network. In: Proceedings of the SIGCHI conference on human factors in computing systems (CHI '14). ACM, New York, pp 3133-3142. https:// doi.org/10.1145/2556288.2557415

Zhou L, Parker AT, Smith DW, Griffin-Shirley N (2011) Assistive technology for students with visual impairments: challenges and needs in teacher's preparation programs and practice. J Vis Impair Blindness 105(4): 197-210

Zhou L, Griffin-Shirley N, Kelley P, Banda DR, Lan WY, Parker AT, Smith DW (2012) The relationship between computer and internet use and performance on standardized tests by secondary school students with visual impairments. J Vis Impair Blindness 106(10):609-621

\section{IT/ICT in Mathematics Teaching and Learning}

Technologies in Mathematics Education 